\title{
Development of a system of monitoring the positioning of a mobile robot for collection of variables in non-structured via Zigbee
}

\author{
Jonathas Tavares Neves ${ }^{1}$, Moisés Pereira Bastos²
}

\author{
${ }^{1,2}$ Universidade do Estado do Amazonas. Avenida Darcy Vargas, 1200 - Parque 10. Manaus - Amazonas - Brasil. \\ Email: jonathastavaresneves@hotmail.com, mpbastos@uea.edu.br
}

Received: August $16^{\text {th }}, 2016$

Accepted: September $27^{\text {th }}, 2016$

Published: December $22^{\text {th }}, 2016$

Copyright $@ 2016$ by authors and Institute of Technology Galileo of Amazon (ITEGAM). This work is licensed under the Creative Commons Attribution International License (CC BY 4.0).

http://creativecommons.org/licenses/by/4.0/ c) (i) (2) Open Aces:

\begin{abstract}
Mobile robots surface exploration are being more used everyday in the world. This application is growing to scientific research areas about environment natural aspects and also to weather study applications. However, the way of localization of these robots and the reception of these informations are still a problem to be solved for non-structured environments. On this present project an autonomous mobile robot was desenvolved for meteorological measurements from a Radio Controled Car. So, the first alteration done was the adaptation of the mechanical structure to different kinds of grounds. After that was established a wireless communication between the mobile and a fix base where tha data obtained can be visualized on a screen. In turn, a tire with amphibious characteristics was elabored on SolidWorks software and the Sethi 3D printer. Also, EPS material was utilized for the vehicle buoyancy. The wireless communication was done between two Xbee PRO S1 and the supervisory system was desenvolved on LabView platform where the GPS SIM39EA was used for the georeferencing. With that, the physical assembly for traction of the robot, navigability and capability of skip obstacles in front of it were tested. The data were colected by the vehicle through the sensors DHT11, BMP180 and through the GPS and were trasmited via xbee to the base where they were visualized on a screen by the user.
\end{abstract}

Keywords: Mobile Robot, Supervisory System, Zigbee.

\section{Elaboração de um sistema de monitoramento do posicionamento de um robô móvel para coleta de variáveis em ambientes não-estruturados via Zigbee}

\section{RESUMO}

Robôs móveis para a exploração de superfícies estão sendo mais utilizados a cada dia no mundo. Esta aplicação vem crescendo para áreas de pesquisa científica sobre aspectos naturais do ambiente como também para aplicações ao estudo do clima. Contudo, a forma de localização desses robôs e recepção dessas informações colhidas ainda representam uma problemática a ser resolvida em ambientes nãoestruturados. No presente projeto desenvolveu-se um robô móvel autônomo híbrido para medição meteorológica a partir de um carrinho de controle remoto. Com isso, a primeira alteração feita foi da estrutura mecânica do veículo para a adaptação em diferentes tipos de terreno. Após isso, estabeleceuse uma comunicação wireless entre o móvel e uma base fixa, onde visualiza-se os dados obtidos em uma tela. Por sua vez, elaborou-se uma roda com características anfíbias por meio do software solidworks e a impressora 3D as Sethi. Também, utilizou material EPS para a flutuabilidade do veículo. A comunicação wireless foi efetuada entre dois xbee PRO S1 e o sistema supervisório foi desenvolvido na plataforma Labview. Onde usou-se o GPS SIM39EA para georeferenciamento. Com isso, testou-se a montagem física do robô para tração, navegabilidade e capacidade de se desviar de obstáculos à sua frente. Os dados coletados pelo veículo por meio dos sensores DHT11, BMP180 e pelo GPS foram transmitidos via xbee para a base onde foram visualizados em uma tela pelo usuário.

Palavras Chaves: Robô Móvel, Sistema Supervisório, Zigbee.. 


\section{INTRODUÇÃO}

O território amazônico por ser um clima equatorial é composto por variações em sua temperatura e umidade. Possui, também, diferentes tipos de relevos, tornando-se, muitas vezes, de difícil acesso aos seres humanos, ao se tratar de áreas de mata virgem ou zonas não habitadas. Um de seus aspectos naturais é a facilidade da proliferação de insetos que transmitem doenças ao homem, como por exemplo o Anopheles que é o mosquito transmissor da malária. Com isso, a floresta amazônica torna-se um ambiente propício a pesquisas relacionadas a temas como: fauna, flora, ocupação humana nativa, climatologia e etc. [1].

O levantamento de dados na Amazônia, tratando-se de aferições meteorológicas, é feito in loco. Os dados são coletados, analisados, tratados e retransmitidos para estações ou bases meteorológicas. Muitas dessas formas de coleta e retransmissão dos dados são feitos por torres de coleta, como é o caso da torre ATTO (Amazon Tall Tower Observator) [2]. Dessa forma, novas tecnologias de exploração são interpostas entre o homem e meio para que não aja uma exposição direta do ser humano e também para a redução do impacto ambiental naquele ecossistema.

A exploração de ambientes não-estruturados, como o caso de florestas, por robôs móveis tem sido objeto de intenso estudo nos últimos anos devido à sua crescente aplicação. Em referência à exploração de ambientes de difícil acesso para o ser humano, encontram casos menos divulgados, como a exploração de ambientes com características florestais. Este é o caso da Amazônia brasileira [3].

Tendo em vista isso, o presente trabalho objetiva a construção física de um robô móvel autônomo, no qual será embutido um sistema para o monitoramento geográfico do mesmo, onde disponibilizará a informação da longitude e latitude.

O desenvolvimento de um sistema de coleta de dados meteorológicos em um ambiente não-estruturado, também fará parte do desenvolvimento do projeto em questão, visando uma possível aplicação na região da floresta amazônica.

\section{REVISÃO BIBLIOGRÁFICA}

Os robôs móveis são dispositivos de transporte automático, ou seja, são plataformas mecânicas dotadas de um sistema de locomoção capazes de navegar através de um determinado ambiente de trabalho, dotados de certo nível de autonomia para sua locomoção. Suas aplicações podem ser muito variadas e estão sempre relacionadas com tarefas que normalmente são arriscadas ou nocivas para a saúde humana, em áreas como a agricultura, no transporte de cargas perigosas ou em tarefas de exploração solitárias ou cooperativas junto a outros veículos não tripulados.

Exemplos clássicos são o translado e coleta de materiais, as tarefas de manutenção de reatores nucleares, a manipulação de materiais explosivos e a exploração subterrânea [4].

Esse tipo de robô deve possuir elementos a bordo, que o faça ser capaz de reconhecer e se adaptar aos diferentes tipos de solo, desviar de obstáculos, encontrar trajetória entre pontos inicial e final de uma dada excursão, receber e cumprir ordens enviadas remotamente, entre outras. Para isso deve dispor de um conjunto de sistemas mecânicos, elétricos, eletrônicos, computacionais, de sensoriamento e de comunicação que sejam um auxílio de grande vantagem para o homem, onde realizem tarefas pré-programadas, pela qual, possa ser executada uma supervisão humana [5].

Um dos meios utilizados na automação industrial, residencial e robótica para a comunicação é através do Zigbee.

As bases da tecnologia denominada hoje por ZigBee foram estabelecidas no protocolo Home RFLite criado pela Philips. A tecnologia foi pela primeira vez apresentada ao público com o nome de ZigBee em Julho de 2005. O nome ZigBee veio da analogia entre o funcionamento de uma mesh network e a maneira como as abelhas trabalham e se deslocam. As que vivem numa colmeia voam em zig zag, de modo que quando voam em busca de néctar comunicam com outras abelhas da mesma colmeia, dando informações sobre a distância, direção e localização de alimentos [6].

\section{MATERIAIS E MÉTODOS}

O robô foi elaborado com um chassi híbrido e rodas ajustáveis. Possui sensores meteorológicos, como também, é composto por sensores de distância. Ele é localizado através de um módulo GPS e a sua comunicação com a base é feita por ZigBee, pela qual ele transmite os dados coletados. A interface de comunicação com o usuário está alocada em um computador e nela mostra os dados de acordo com o período de coleta.

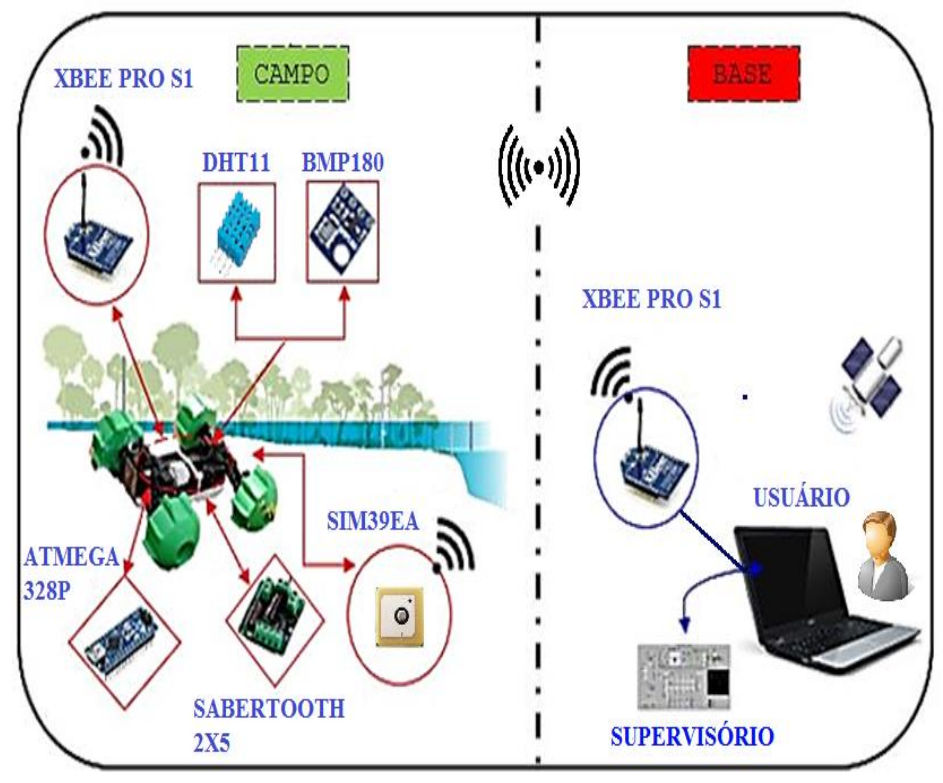

Figura 1. Arquitetura Funcional da Proposta.

Fonte: Os autores, (2016).

A arquitetura trata da visão geral do funcionamento do trabalho proposto. Conforme a figura 1 vê-se a aplicação do projeto em questão para dois tipos de ambientes: Base e Campo. 


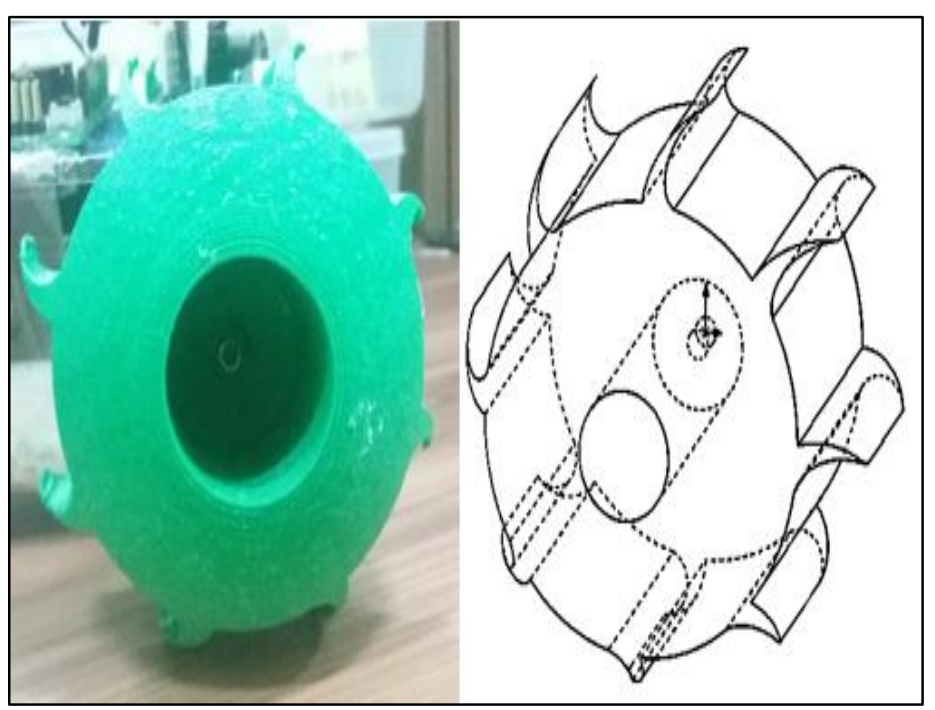

Figura 2.Roda Desenvolvida.

Fonte: Os autores, (2016).

Uma das principais alterações feitas na parte mecânica do robô móvel foi adaptação do veículo para ele se locomovesse sobre superfície líquida e sólida. Dessa maneira, projetou-se uma roda, apresentada na figura 2, para habilitar o veículo a andar nesses tipos de terrenos, onde seu design visa o deslocamento de massa entre o eixo central do pneu e os sulcos tangentes a ele. Isso quer dizer que, enquanto o veículo se mover em rios, igarapés ou pântanos o perfil de aderência do pneu fará com que ele funcione com o mesmo princípio de hélices de navios e barcos.

As hélices ao serem posicionadas no sentido do movimento da roda dão impulso ao veículo. Similarmente, o tamanho da roda é definido baseado no torque do motor, onde no veículo utilizado só existe um motor de corrente direta, pelo qual fornece a rotação para as quatro rodas através de um eixo cardã.

Para o processo de fabricação da roda utilizou-se a impressora 3D sethi 3D Aip . Nela, compilou-se o desenho no formato stl (Stereo Lithograpy) que foi elaborado no software solidworks 2015. O material usado na impressão foi o ABS (Acrylonitrile Butadiene Styrene). Após isso, foi feita a montagem da peça na estrutura do veículo.

A maneira pela qual o robô compreende o ambiente em sua volta é através da aquisição de dados. Estes são provenientes dos sensores meteorológicos, conforme a figura 3, sensores ultrassônicos e o módulo GPS. Assim, a participação de cada um desses componentes está diretamente ligada ao seu modo de funcionamento.

A especificação dos componentes usados é:

Um sensor BMP180 (pressão barométrica);

- Um sensor DHT11 (temperatura e umidade);

- Dois sensores HC-SR04 (distância);

- Um sensor SRF02 (distância);

- Um Módulo GPS SIM39EA.

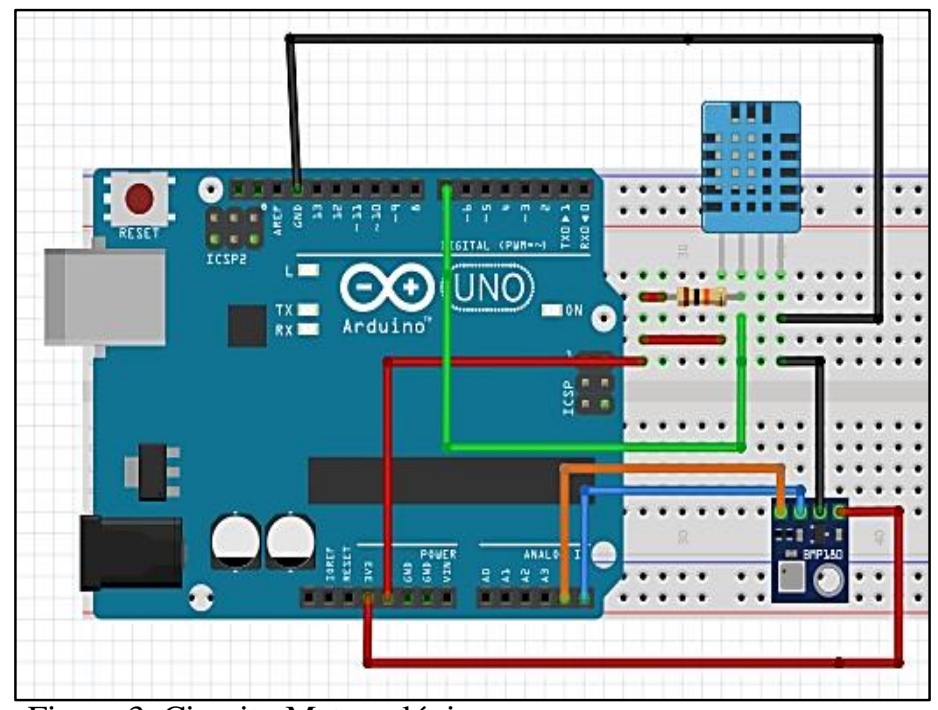

Figura 3. Circuito Meteorológico.

Fonte: Os autores, (2016).

Um dos diferenciais do projeto é o emprego do Xbee Pro S1 da figura 4 para a comunicação de dados, onde envia apenas uma informação por vez para o xbee receptor de modo wireless (sem fio). Logo, o agrupamento desses dados é efetuado pela ordem da leitura dos sensores meteorológicos.

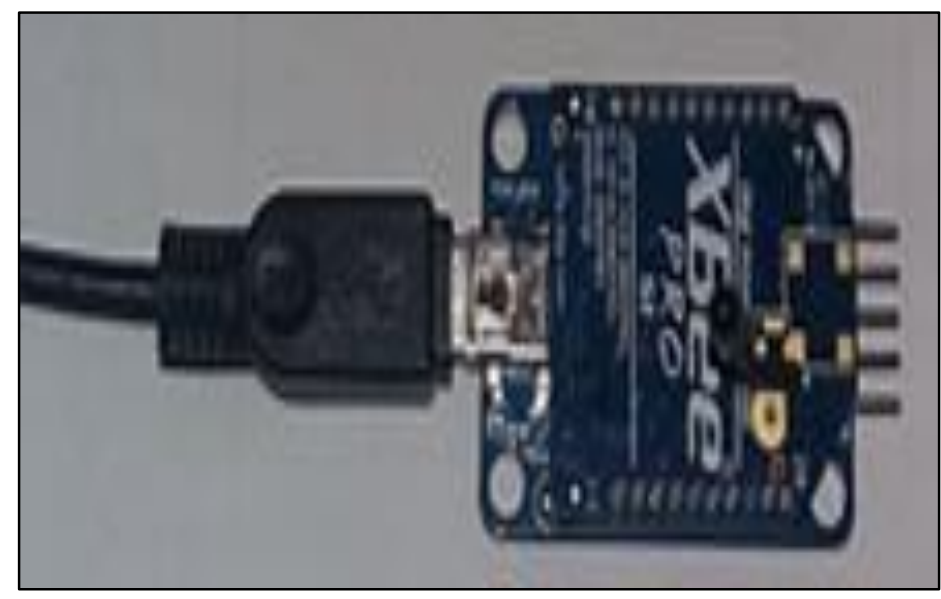

Figura 4. Xbee Receptor.

Fonte: Os autores, (2016).

O sistema supervisório do veículo robótico mostra ao usuário as informações obtidas deste por meio de gráficos e indicadores. Estes são elaborados através do software Labview (Laboratory Virtual Instrument Engineering Workbench) versão 2014.

Basicamente, os dados coletados pelos sensores meteorológicos que são transmitidos pelos Xbee, chegam nos formatos de string e float na porta serial, de acordo com a figura 5, e são compilados no programa. Assim, se estabelece uma conexão da porta de comunicação do PC (Personal Computer) com o VISA Configure Serial Port, que é uma ferramenta de leitura de dados do Labview 


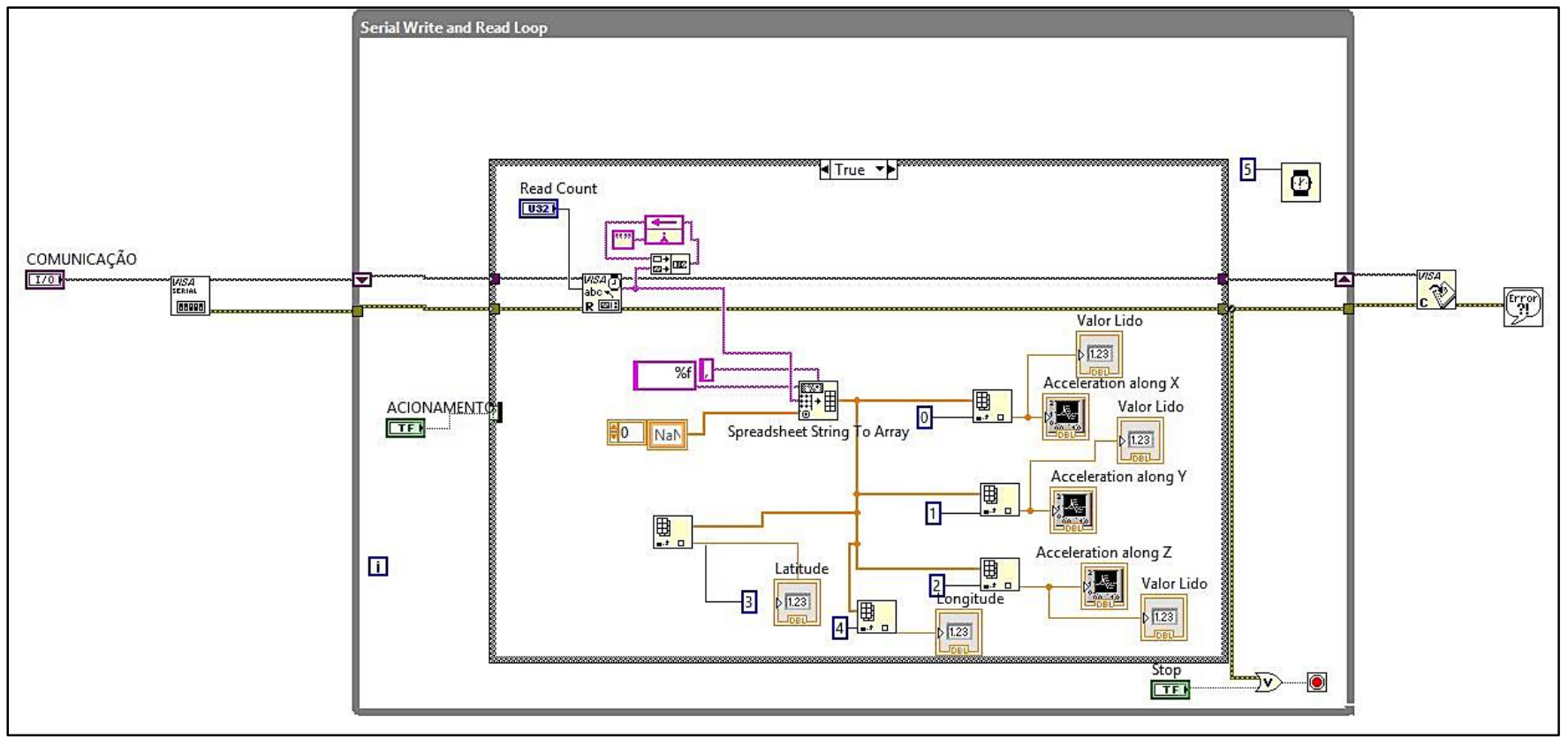

Figura 5. Esquema no labview para a leitura da porta serial.

Fonte: Os autores, (2016).

Para a elaboração do mapa em 2D do posicionamento do robô em tempo real utilizou-se conforme a figura 6 uma ferramenta livre disponibilizada pelo Google Maps e fez-se as alterações para a adequação no presente trabalho. Com isso, os dados provenientes do GPS SIM39EA são manipulados e direcionados como strings para uma segunda estrutura que está encarregada de ler e gerar a forma de visualização da localização do veículo. Após receber os dados, usa-se o Array to Spreadsheet String na conversão deles em um formato que possa ser lido em agrupamento.

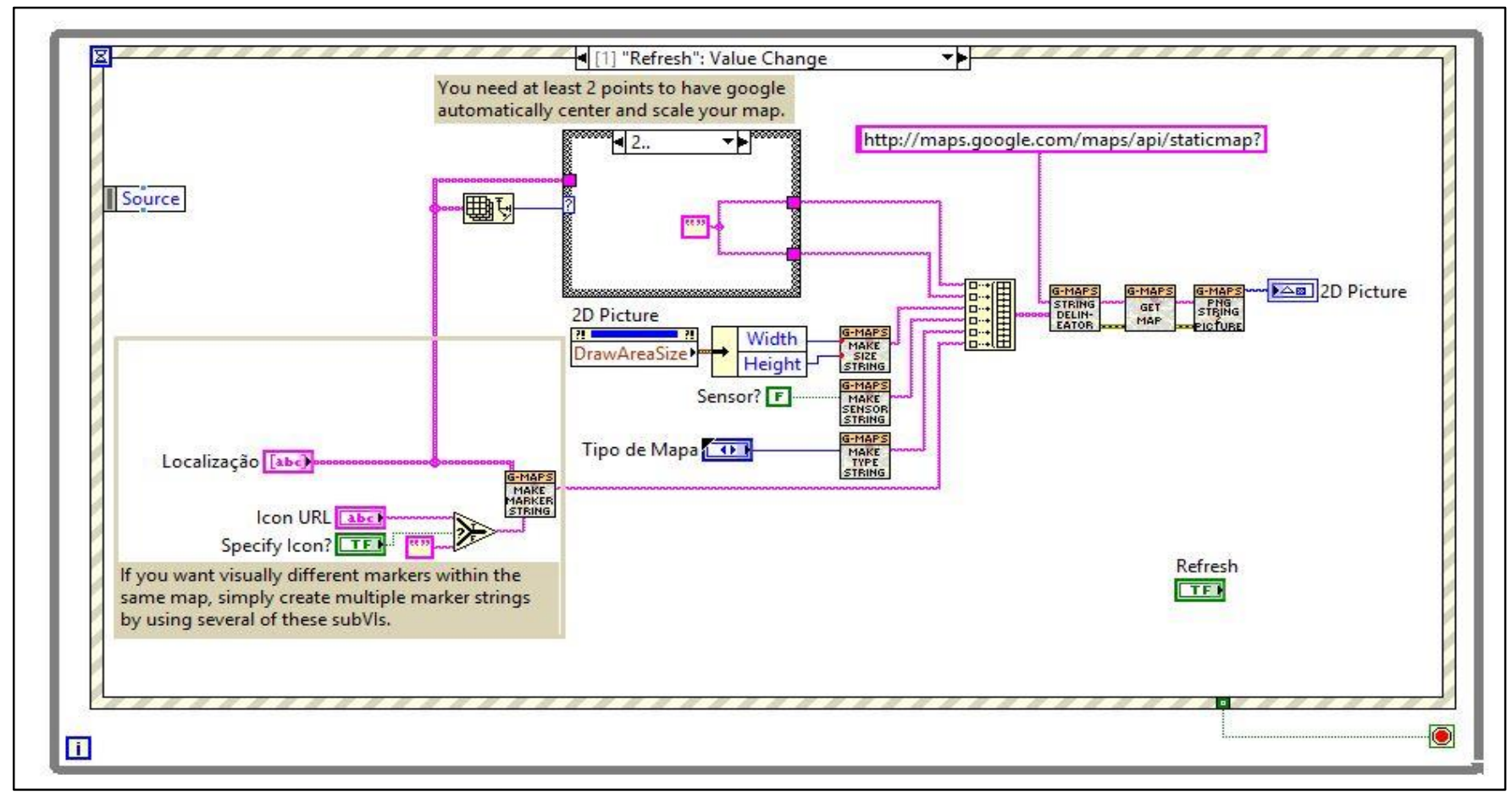

Figura 6. Visualização do Posicionamento pelo Google Maps.

Fonte: Os autores, (2016). 


\section{RESULTADOS E DISCUSSÕES}

Um dos resultados principais foi a montagem da estrutura robótica, conforme figura 7, sendo agrupada em duas camadas de ACM (Alumínio Composto), pelo qual, o circuito elétrico foi distribuído. Na camada superior encontram-se os dispositivos de comunicação wireless e os de medição, tais quais os sensores meteorológicos e o módulo GPS. Já na camada ou placa inferior, os componentes eletrônicos montados são responsáveis pelo controle de velocidade e de posição, junto com o microcontrolador.

Para a flutuabilidade do veículo, utilizou-se material EPS (Poliestireno Expandido) na carcaça inferior. Também, para a proteção do carrinho revestiu-o com Etil Vinil Acetato.

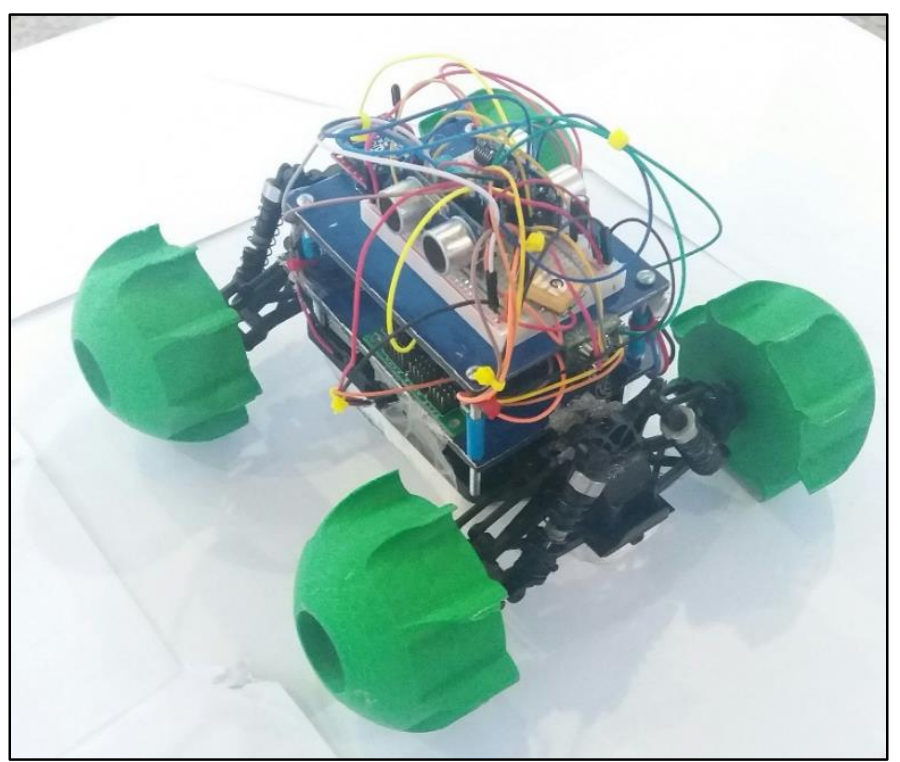

Figura 7. Robô Móvel Autônomo Híbrido.

Fonte: Os autores, (2016).

No software XCTU na seção de working mode visualizase o painel referente as medições tomadas em campo, conforme figura 8. Os dados estão agrupados em leituras no formato string no painel esquerdo da tela (Console log) e hexadecimal no painel direito. Após isso, pode ser gerado um documento que descreve a leitura, a porta de comunicação, o protocolo de comunicação e a data em que foi efetuado esse teste.

\begin{tabular}{|c|c|c|c|}
\hline 50 & 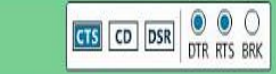 & $\begin{array}{c}\text { AT Console } \\
\text { Status: Connected }\end{array}$ & $\begin{array}{l}\text { Tx Byytes: } 0 \\
\text { Rx Byytes: } 4334\end{array}$ \\
\hline Console log & \multicolumn{3}{|c|}{ (2) (i) (i) (i) } \\
\hline Termperatura (graus & \\
\hline (elsius): 20.00 & \multicolumn{2}{|c|}{$73293 A 2832302 E 303080$} & \\
\hline Lendo sensor: OK & \multicolumn{3}{|c|}{ OA 4C 65 6E 64 6F 287365 6E 73 GF $723 A 28$ \&F 4B 00} \\
\hline Unidade $(\%): 62.00$ & \multicolumn{3}{|c|}{$0 A 55606964616465202825293 A 2036322 E 303000$} \\
\hline Temperatura (graus & \multicolumn{3}{|c|}{ OA $5465607065726174757261202867726175732043656 C 736975$} \\
\hline (elsius): 20.00 & \multicolumn{3}{|c|}{$73293 A 2032302 E 303000$} \\
\hline Pressao : $100860 \mathrm{~Pa}$ & \multicolumn{3}{|c|}{ OA $5072657373616 \mathrm{~F} 203 \mathrm{~A} 2031303038363020506100$} \\
\hline
\end{tabular}

Figura 8. Comunicação Wireless via Zigbee

Fonte: Os autores, (2016).
No acionamento do programa completo, as estruturas de comando do labview executam-se de maneira simultânea, pelas quais os dados de cada gráfico ou imagem gerada estão agrupados sem nenhuma interferência entre si. Portanto, após a configuração de baixo nível das telas, onde não há necessidade da intervenção ou atuação direta do usuário, torna-se possível a visualização por meio de um sistema supervisório apresentado na figura 9 .

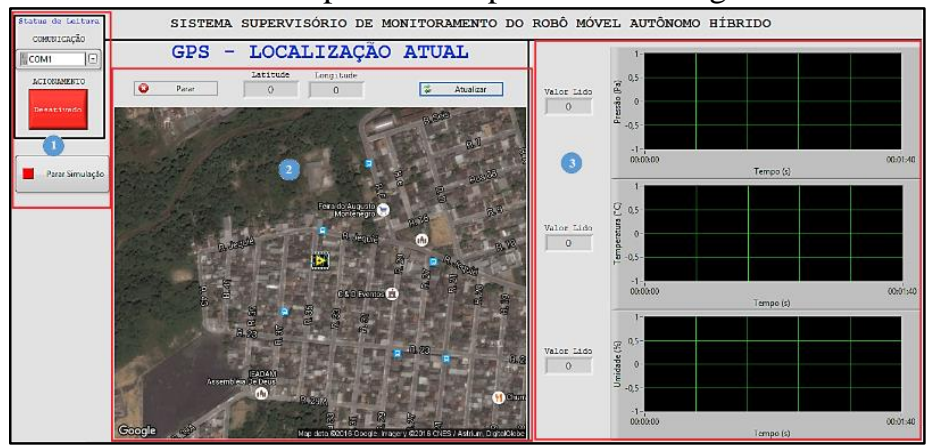

Figura 9. Sistema Supervisório.

Fonte: Os autores, (2016).

Levando em conta a constituição do solo arenoso, do relevo de planície e vegetação aberta o terreno foi configurado para a realização dos testes. Primeiramente, fixou-se a limitação do terreno, através de toras de madeira, com área de $4 \times 2 \mathrm{~m}^{2}$, sendo assim, estipulou-se um caminho para ser percorrido pelo robô. Neste percurso os obstáculos a serem testados são ordenados em conformidade com os níveis de dificuldade. Do lado esquerdo da pista, posicionam-se os corpos rígidos pela qual o veículo deverá se desviar, ao todo, compõe-se três elementos com dimensões distintas. Do lado direito, colocou-se rampas para simulem o movimento de subida e descida do robô e, também, uma declividade onde acumula-se água, pela qual, averígua-se a capacidade do mecanismo de flutuabilidade.

Os obstáculos físicos postos na trilha a ser percorrida são elementos que estão presentes em uma floresta tropical, como a floresta amazônica. Derivados de árvores nativa são exemplos de estruturas encontradas na mata, além da folhagem que está disposta por todo o percurso. Conforme a figura 10, observa-se os itens descritos e a seta de direcionamento do sentido de rodagem do veículo.

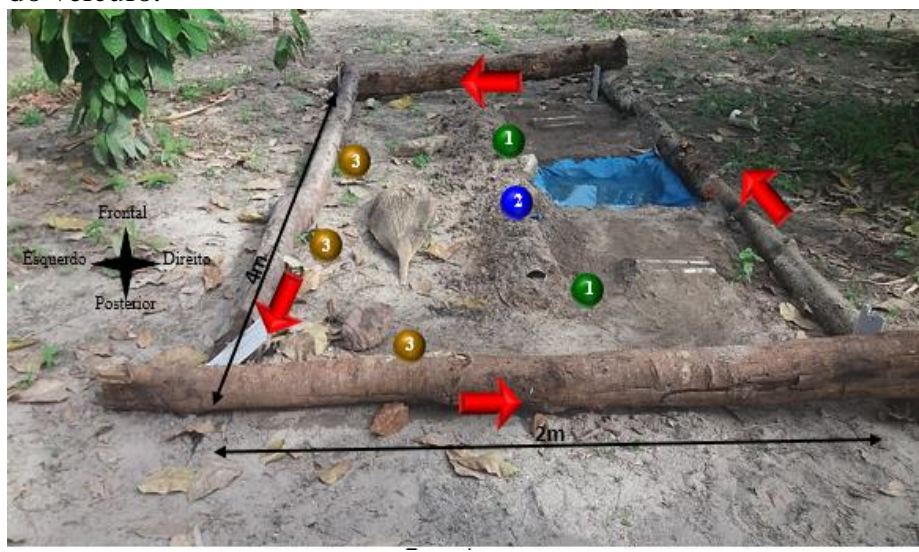

Figura 10. Pista de Testes.

Fonte: Os autores, (2016). 
Na figura 10 o percurso do robô é efetuado no sentido anti-horário, onde ele percorre as rampas de níveis descritas com o número 1 (simulando os diferentes relevos), a declividade com o acúmulo de água (destinado ao teste anfíbio, onde tem dimensões de 800x800 mm) e os obstáculos que representam corpos sólidos dispostos na floresta. As dimensões da pista são 2x4m, no qual os testes são conduzidos em solo arenoso, seco, resguardando o aparelho de incidência direta de luz solar evitando-se um superaquecimento dos componentes, onde a distância do veículo até a base é aproximadamente $26 \mathrm{~m}$ de distância em linha reta. A coleta dos dados meteorológicos é efetuada tanto com o carrinho em movimento quanto parado, assim como a percepção do posicionamento do mesmo que chega em formato de latitude e longitude ao usuário.

\section{CONCLUSÃO}

O desenvolvimento de um robô móvel com autonomia para o direcionamento de uma rota de tráfego por intermédio do sensoriamento a distância e lógica reativa que se desloque num ambiente que simula uma floresta (por meio de uma mata de vegetação secundária) e também em terrenos que possuam água (de acordo com a característica hidrográfica da região amazônica) com o objetivo de medir a variação dos dados meteorológicos de pressão atmosférica, temperatura local e umidade relativa do ar visando uma possível aplicação ao estudo do clima, conforme o estabelecido na Conferência das Partes da Convenção sobre o Marco da ONU (Organização das Nações Unidas) sobre a Mudança Climática 2015 (COP21/CMP11), foi realizado no projeto em questão.

Para que fosse possível a locomoção do robô nesse ambiente conhecido, porém, não-estruturado foi desenvolvida a roda híbrida. Esta representa a hélice de um navio quando o veículo está emerso, onde atua em conjunto com o material EPS que está na parte inferior do carrinho. As dimensões estão em conformidade entre a relação da distância do veículo com o solo e o torque do motor. O teste da conexão direta da bateria com o motor e o efeito do giro deste transferindo o movimento para as engrenagens e, após isso, adjacentes conectados a roda mostraram a capacidade móvel em terreno com atrito relativo aos relevos amazônicos. Também, verificou-se no teste de flutuabilidade em um tanque com profundidade de $300 \mathrm{~mm}$ a capacidade de movimentação sobre a água.

Os itens da estrutura eletroeletrônica foram fixados visando melhor aproveitamento de sua funcionalidade, com isso, os sensores, gps e o módulo xbee estão dispostos no nível superior da placa de ACM, já que oferecem menor ruído e baixa interferência de sinal por estarem dispostos na parte mais elevada do robô. O microcontrolador ATMEGA328P e o regulador de velocidade Sabertooth $2 \times 5$ estão instalados no nível inferior, onde permitem uma interação mais efetiva com o motor, servo motor e os demais elementos. Constatou-se assim, a necessidade da configuração de duas colunas com tensões específicas para a alimentação dos referidos componentes, pela qual foram utilizadas as colunas vermelhas da miniprotoboard.

Por sua vez, a rede de comunicação entre os dispositivos xbee PRO S1 transmissor e o receptor foi estabelecida como o previsto, onde, não apresentou interferência nos dados metereológicos medidos pelos sensores DHT11 e o BMP180, uma vez que a distância de comunicação estabelecida no teste foi de aproximadamente $26 \mathrm{~m}$, pela qual, não ultrapassou os limites de operatividade do comunicador $x b e e$ estabelecido no datasheet deste componente na seção de comunicação indoor.

\section{AGRADECIMENTOS}

A Universidade do Estado do Amazonas (UEA), ao Instituto de Tecnologia e Educação Galileo da Amazônia (ITEGAM), ao Núcleo de Robótica e Automação da GRAEST-UEA e a todos os professores envolvidos que ajudaram na realização desse projeto.

\section{REFERÊNCIAS}

[1] CÁSSIA, B. Rita de. Malária no Brasil: panorama epidemiológico na última década. $\boldsymbol{C a d}$. Saúde Públ, SciELO Public Health, v. 11, n. 1, p.128-136, 1995.

[2] ANDREAE, M. et al. The amazon tall observatory (atto) in the remote amazona basin: overview of first results from ecosystem ecology, meteorology, trace gas, and aerosol measurements. Atmos. Chem. Phys. Discuss, v. 15, n. 8, p. 1159911726, 2015.

[3] SANTOS, A. V. Controle de capotagem e deslizamento de sistemas robóticos móveis em terrenos acidentados. 2007

[4] SECHI, H. Uma Introdução a Robôs Móveis. [S.1]: Argentina, 2008.

[5] SANTOS, K. d. S. Sistema de Navegação Autônoma para Robôs Móveis Baseado em Arquitetura Híbrida: Teoria e Aplicação. Tese (Doutorado) - Dissertação (Mestrado) Universidade Federal de Itajubá-Programa de Pós-Graduação em Engenharia Elétrica, Itajubá, 2009.

[6] SALEIRO, M.; EY, E. Zigbee-Uma abordagem prática. [S.1.:s.n.], 2009. v. 26. 2014. 